Historic, Archive Document

Do not assume content reflects current scientific knowledge, policies, or practices. 

$-6.39$

IIBF $\pi Y$ Iiti

+ JUN 5 19:

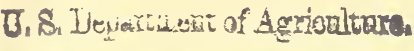

$\int \ln (\operatorname{liche}=$

I 929

Emilie H. Kitson

KIT GARDEN

Springfield

gassachusetts 



\section{Kit Garden Dahlias}

Emilie H.Kitson 9 Irvington Street Springfield, Massachusetts

Order Early-Your selection of varieties will be reserved upon receipt of your order and shipment made after early April, unless otherwise requested.

Guarantee-Stock that is true to name, in good growing condition upon leaving our hands, and carefully packed for safe transit to you.

You are cordially invited to visit Kit Garden, located at Crescent Lake,-on the Shaker Road,two and a half miles south of East Longmeadow, Mass. 



\section{Groming the Dahlia}

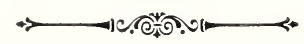

\section{LOCATION}

Give dahlias a place by themselves. Avoid shade if possible for it delays the blooming period. Space at least three feet apart. Straight rows are the most convenient for cultivating.

\section{PLANTING}

Plant six inches deep, tuber laid flat with sprout pointing up. Cover tuber for half the depth of the hole, firm the soil but do not pack it hard. Place a card board cuff so that the plant will come up inside. Press the cuff $2^{\prime \prime}$ into the soil and let it stand $2^{\prime \prime}$ above, to keep out cut-worms. As the plant grows, fill the hole till the ground is level and raise the cuff proportionately. When cutworms are gone, remove cuffs.

\section{FERTILIZER}

After the planting is done, broadcast longside the rows, commercial fertilizer 4-6-10 and cultivate into the soil. When blossoms begin to form, broadcast Sheep fertilizer and rake in. Do not use Sheep early in the season. It is of more value as a tonic when buds are forming.

\section{CULTIVATING}

The one item of more importance than all else upon which the dahlia depends for its well-being, is cultivation. Our practice at Kit Garden is to keep a dust-mulch constantly on the growing rows.

After a rain as soon as the soil becomes dry enough to work, the cultivators go through the rows breaking up the soil before it has a chance to bake under the Sun's heat. Later it is fined down with the rake.

This system of cultivating starts as soon as the rows are planted. The dust-mulch keeps the moisture in the under-soil and the air has a chance to work down into it and keep it sweet and fresh.

\section{PRUNING AND DISBUDDING}

The first remark that we hear from visitors at Kit Garden more often than any other is, "What quantities of blossoms and how big they 


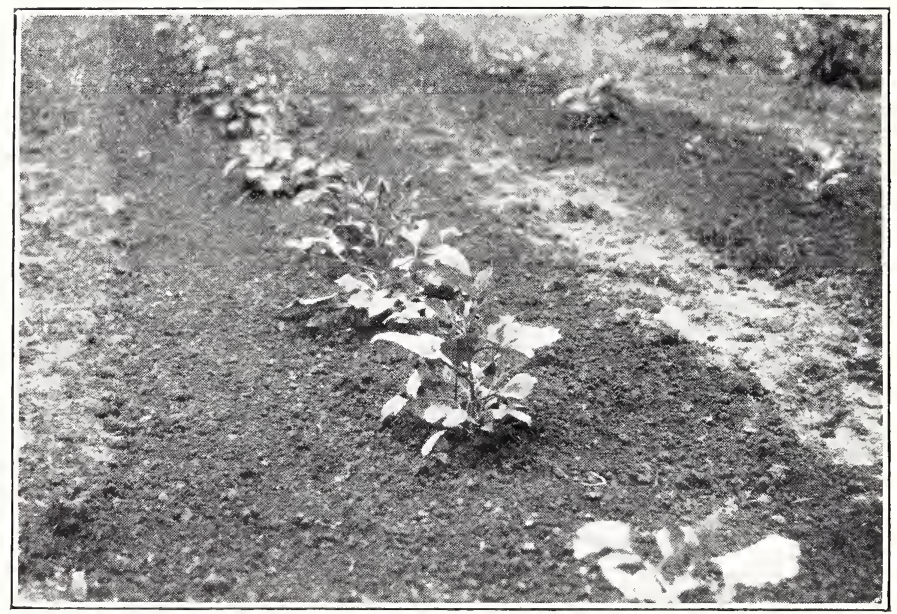

Picture A

The Picture A above shows cultivated row of young plants.

are." Then they ask if we feed special fertilizer to get such results. The next thing that catches their attention is that the bushes are short.

Our reply to their questions is that we grow our bushes short by pinching out, and we keep the bushes balanced by repeated pruning; which together with disbudding, gives the quantity and size of bloom. We do not feed special fertilizer for size. Dahlias that grow very large for us do so from their own inherent traits.

The accompanying pictures illustrate our method of handling the plants. When the little plant has grown four or five pairs of leaves the center of the plant is pinched out, that is, topped.

Note arrow in Picture B, before pinching, (see Picture B at bottom of page 5) and (arrow) in Picture $\mathrm{C}$, after pinching. (see Picture $\mathrm{C}$ on page 6$)$.

Immediately side shoots start to grow out of the leaf crotches below.

In a short time the plant looks like Picture D (page 7). Arrow points to spot on the plant that corresponds to where it topped as 
shown in Picture C. The upright branches, making a beautiful shapely plant are all out of the original four or five pairs of leaves.

These branches come to their terminal cluster of blossom buds and at Kit Garden we disbud each cluster, leaving one bud only of the three, usually the center one.

If this disbudding is done when the buds are barely big enough to rub off with the fingers, the stem will heal over and leave no scar and the blossom will grow to maturity on a good stem. If the stem is followed down into the bush and the little shoots pruned out of several leaf crotches it will make a fine long stem to cut with the blossom.

While this blossom is maturing, the side shoots below the pruning will be growing to the r terminal buds and will be ready soon to make bloom to succeed the first one cut. This procedure carried out all over the bush, brings a succession of bloom on good stems.

Now aside from the fact that disbudding gives size to the blossoms, there is another point that with us has more weight in the argument

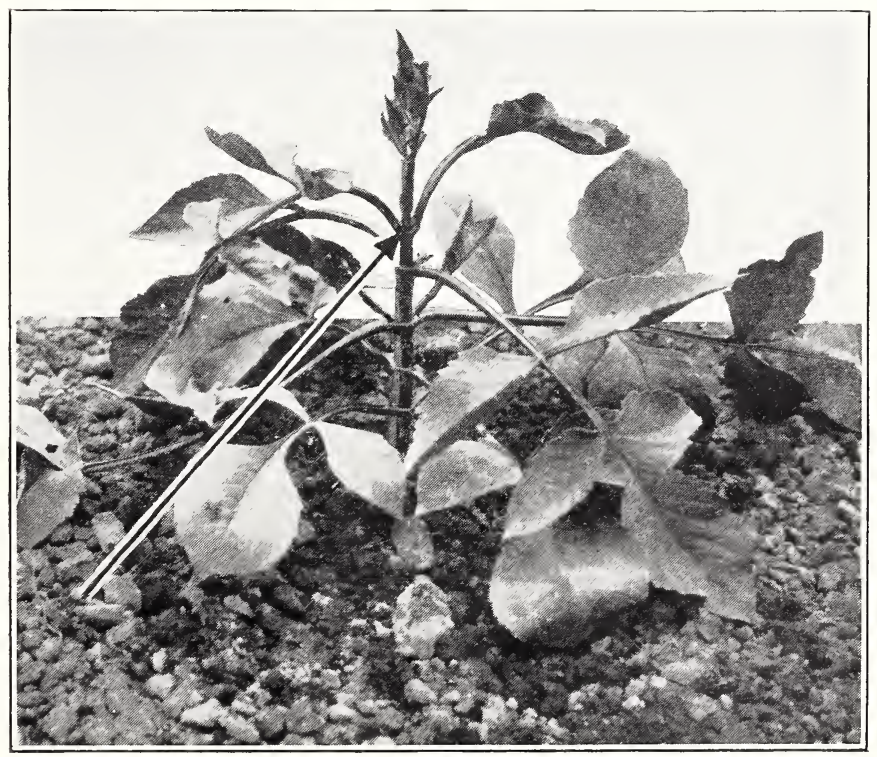

Picture B 


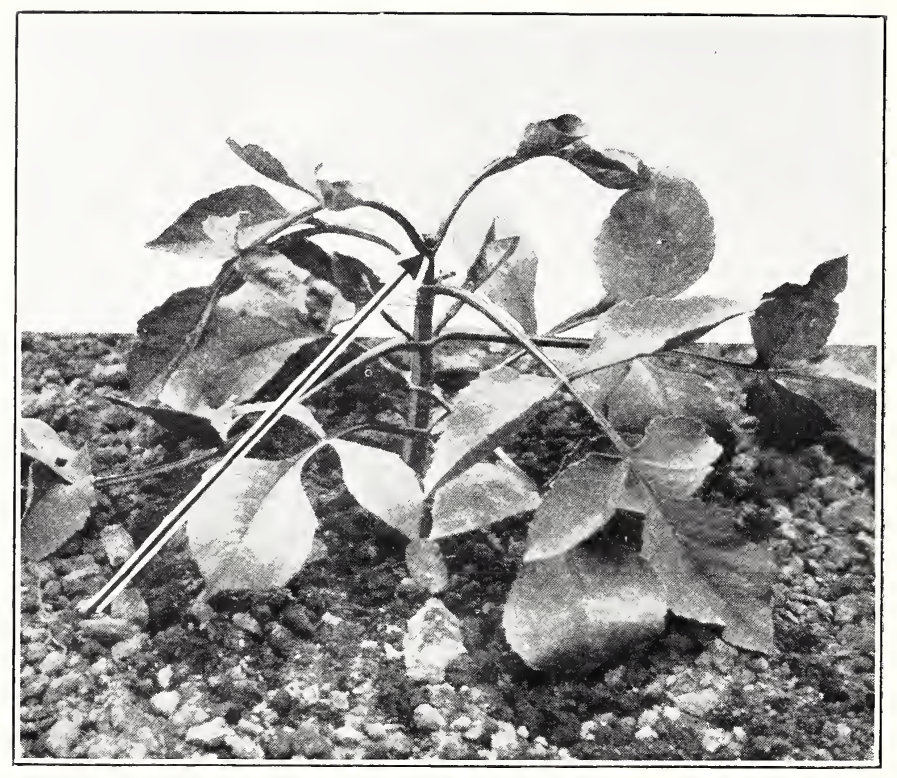

\section{Picture C}

for disbudding. Note Picture E (page S), arrow Y shows a bloomcluster that was left not disbudded to illustrate the point we wish to emphasize.

The large blossom in the picture (arrow $\mathrm{Y}$ ) is the center one of a cluster of three. The center bud matures first and while it is opening its blossom, the two side buds extend their stems far above the center blossom before they begin to unfold. If the whole cluster is cut when the center blossom is just right, it makes an awkward spray that is not artistic. And the two side buds will not open to any degree of perfection after cutting.

If the center blossom is cut alone so not to sacrifice the other buds, note in the picture how short its stem will be. Such a stem will allow for no artistic arrangement in a vase that is proportionate to the size of the flower.

Suppose one bud is removed leaving two buds to mature, again there will be an uneven development. On the right side of Picture E (arrow $Z$ ) is such a two-cluster with one bud about to unfold its color, 
and another bud much smaller on a stem that will extend higher before the blossom unfolds.

On the left side of Picture E (arrow $\mathrm{X}$ ) note the single bud on a long stem that may be cut way down in to the bush, with leaves, due to the disbudding. This is the way we like them at Kit Garden.

Another advantage of this method of growing the plants is that it simplifies the matter of staking. If all of one variety are planted in a row, one small stake per varjety or row to hold the name tag, is sufficient.

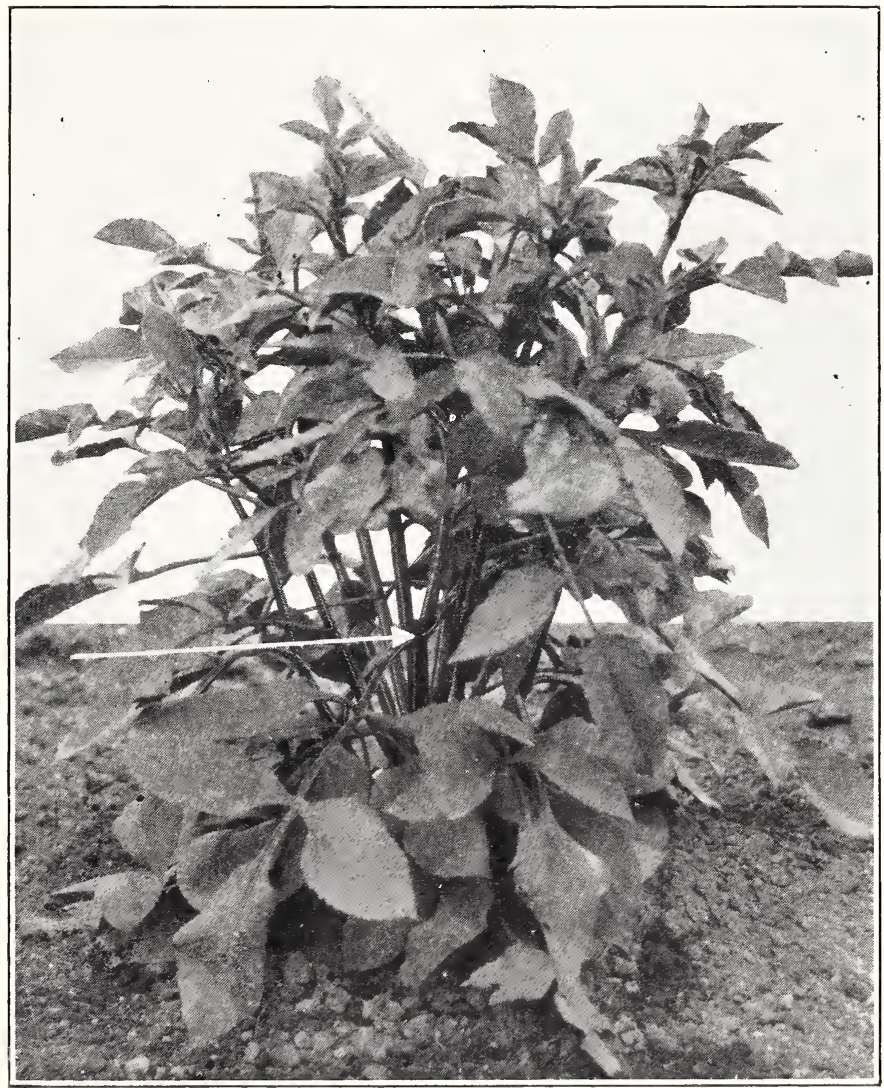

Picture D 


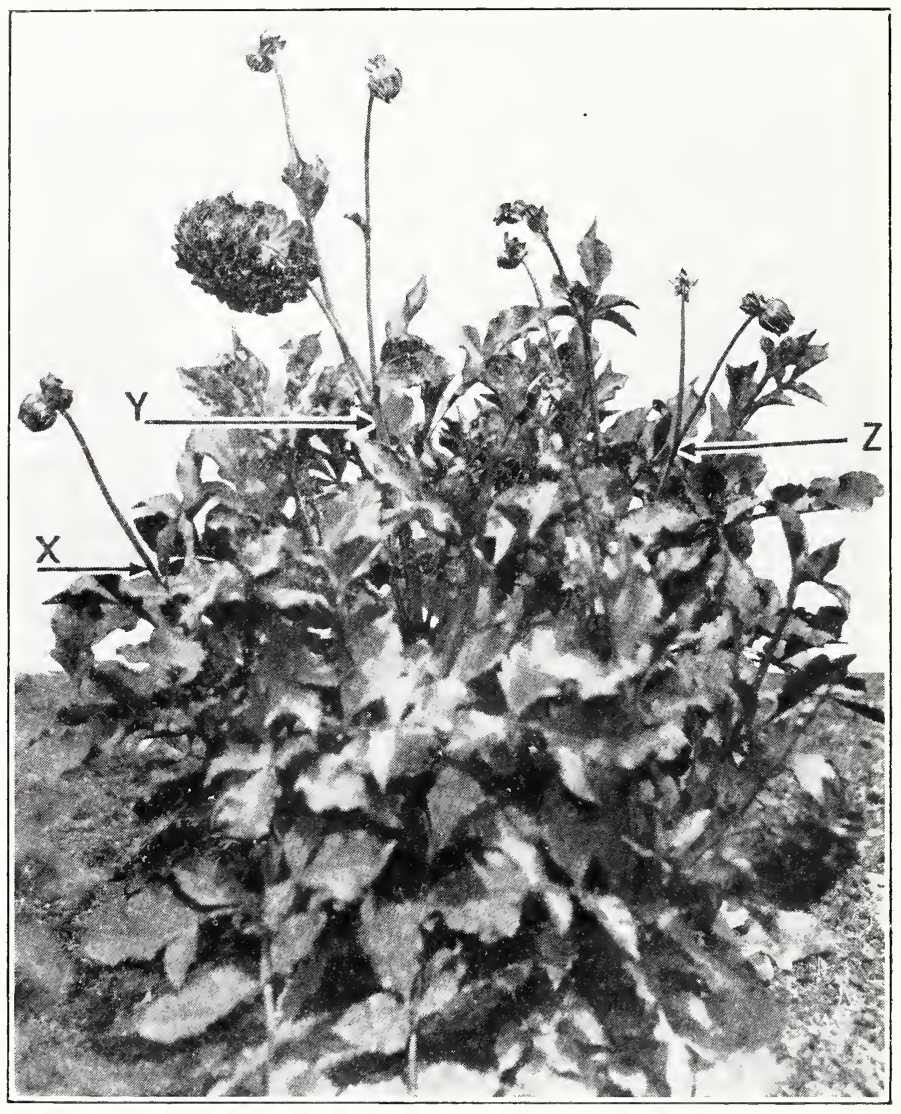

Picture E

We invite your correspondence if there are any points which you wish to ask about. Any helpful hints to meet your particular problem that we can offer are at your service. 


\section{Decorative}

\section{AMUN RA (Seal)}

Copper-orange with reddish center. Large bloom, strong stem. Tuber.

\section{BLACK JACK (Hodgen)}

Dark maroon almost black. Large bloom, good straight stem. Tuber

\section{BLUE LADY (Seal)}

Bluish-lavender. Tuber.

\section{BONAFIN (Kemp)}

Clear picric yellow. Broad petals decidedly revolute, a very round blossom. Tuber.

\section{CHARLES STRATTON (F. \& M.)}

Pale gold shaded with pale rose. Large fluffy type blossom. Tuber

\section{CHARM (Marean)}

Burnt orange outer half of petal, shading to yellow at center. Tuber.

CITY OF TRENTON (F. \& M.)

Glowing tangerine, reverse crushed strawberry-red. Tuber.

\section{CURFEW (Slocombe)}

Clear yellow. Full thick blossom, free bloomers. Tuber.. 1.50

\section{DORIS MAY (Kitson)}

Bronze-rose, deep blue reverse. Medium size bloom. Tuber.

\section{ELLINOR VANDERVEER (Seal)}

Satiny rose-pink. Large. Tuber.

\section{ELITE GLORY (Kennedy)}

Brilliant rich red, immense size. A stunner in the garden and a great exhibition dahlia in "largest bloom" class. Tuber.

\section{ELIZA GLARK BULL (Boston)}

White, one of the best. Tuber.

\section{GOLD (Kitson)}

Clear gold, medium size. Tuber 


\section{GOLDEN WONDER (Thatcher)}

Golden yellow shading to apricot with white tips. Medium size. Tuber

\section{GRACE SHERMAN (M. \& S.)}

Lightpink, base of petals light orange. Thick blossom, free bloomer. Tuber.

\section{HARRY MAYER (Seltsam)}

Rosy-lavender, reverse deeper, giving two color effect. One of the immense ones held erect on gocd stem. Free bloomer, good keeper when cut. A prize winner in "largest bloom" class. Tuber.

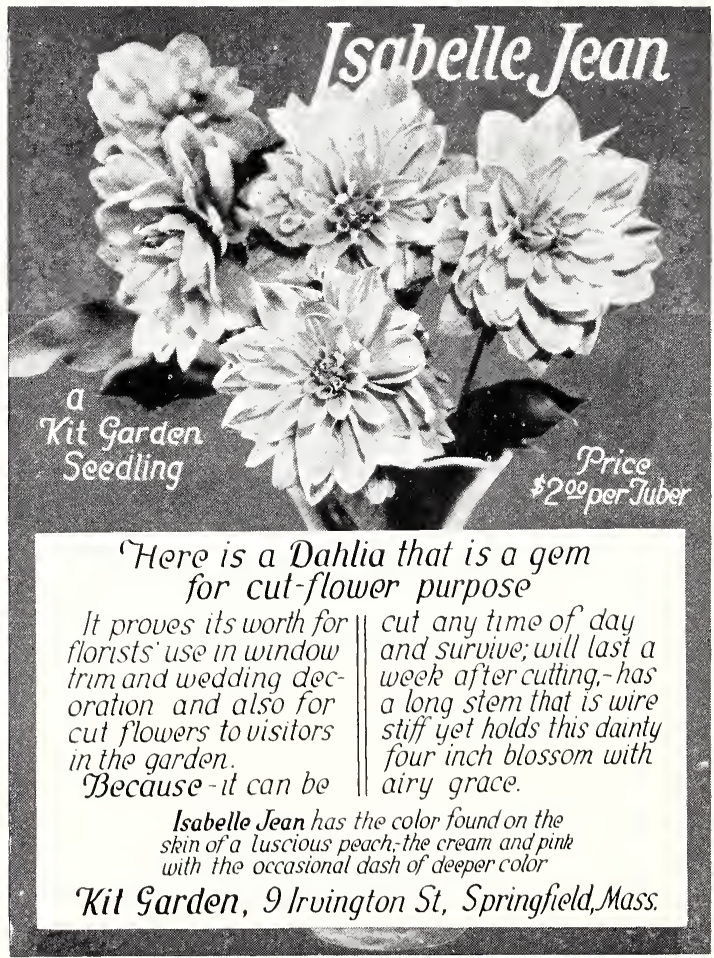

\section{ISABELLE JEAN (Kitson)}

Illustration and description above. Tuber. 


\section{JERSEY'S BEAUTY (Waite)}

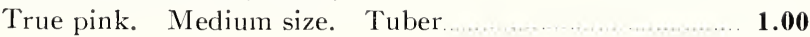

JERSEY'S IDEAL (Waite)

Lavender-pink, more lavender than pink. A recent addi-

tion to the list of "Jersey" winners. Tuber.

JERSE Y'S JEWELL (Waite)

Soft mallow pink. 'Tuber............................................... 2.00

\section{JERSEY'S MAMMOTH (Waite)}

Golden mahogany. A dahlia that lives up to it's name, a sure winner in "largest bloom" class. Tuber....

\section{JUDGE MAREAN (Marean)}

A blending of orange, gold, salmon and yellow with touch of red on tips. Tuber.

\section{KEMP'S LAVENDER (Kemp)}

Pale lavender. Medium size. Tuber

\section{KING TUT (Seal)}

Rich crimson-burgundy, a large velvety beauty that blends well with all the others except bright red ones. Tuber

\section{KITTY DUNLAP (Boston)}

Light shade of American Beauty Rose. Tuber.

\section{MABEL THATCHER (Marean)}

Rich yellow with hint of pink on reverse that gives a warm tone overall. Tuber.

MARGARET MASSON (F. \&. M.)

Silvery rose-pink, one of the big ones. Tuber.

MARGARET WOODROW WILSON (F. \&. M.)

Opalescent pink, large, very pale but a beautiful dahlia.

Tuber

\section{MARMION (Mastick)}

Golden yellow with bronzy suffusion. Immense dahlia, a sure prize winner. Tuber

\section{MISS RUTH GREENOUGH (Greenough)}

Pure white, medium size. Tuber.

\section{MORDELLA (Kemp)}

Apricot-buff with hint of salmon. A long-petaled, highcentered beauty. Tuber. 


\section{MRS. GEORGE C. MEACHEN (Meachen)}

Irridescent shadings of picric yellow and corinthian pink, reverse rose. Tuber.

MRS. I. de VER WARNER (Marean)

Deep mauve-pink, one of the best ever produced, should be in every garden. Tuber.

\section{ORCHID (Kitson)}

Lavender with a pink tone. Tuber.

\section{POLAR SNOW (Marean)}

Pure white, medium size, free bloomer. Tuber

\section{POP S'TEWAR'T (F. \& M.}

Clear light lavender, large, uniform in formation and color, grand stem, a wonderful dahlia. Tuber.

\section{ROBERT TREA'T (Miteller)}

Rich American Beauty Rose, of deep velvety color unlike any other dahlia. Tuber

ROMAN EAGLE (F. \& M.)

Flaming copper, large, making a brilliant spot of color in the garden. Has proved a good seed-bearer with us. Tuber

\section{ROSE FALLON (Harding)}

Old gold, another immense one for the "largest bloom" class. Tuber

\section{SAGAMORE (Badetty)}

Gold, medium size, fine keeping cut flower. Tuber

SANHICAN MAGNET (F. \&. M.)

Amaranth pink, reverse claret. Tuber.

SANHICAN NYMPH (F. \&. M.)

Delicate primrose yellow, reverse of petals tipped fawnrose. A rare exhibition dahlia of unusual solid formation and immense size. Tuber.

SEASHELL (Roach)

Clear shell-pink, a large one. Tuber

\section{THE CRESCENT (Kitson)}

Golden-cream shading to amber-pink, narrow petals twisting show bright pink reverse. Tuber 
THE SURPRISE (Marshall)

Salmon overshadowed with wine tone, early bloomer.

Tuber

WANDA MILLER (Rindfliesch)

Purple, white tips. Tuber.

WINFIELD SLOCOMBE (Slocombe)

Old gold shading to orange center. Tuber

WONDERLAND (Bissell)

Wine-garnet, silver reverse, large. Tuber

WORLD'S BEST WHITE (Murphy)

Cream white. Tuber.

ZENIDA (Kitson)

Brilliant red, medium size cut flower. Tuber

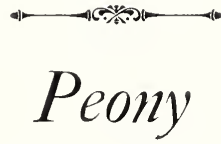

\section{COUNT MANCINI (Kitson)}

Yellow-buff. Opening a yellow which soon becomes overlaid with a flush of thin red giving a buff tone. Under artificial light the yellow is lost and the color appears to be a soft pink. Thick blossom with wide petals, profuse. bloomer. Tuber.....

\section{MISS LYNN (Marshall)}

Clear pale pink. Long-petaled, exhibition variety. Tuber $\mathbf{3 . 0 0}$

\section{WILDROSE (Kemp)}

Silvery pink face, reverse plum. A lovely, medium size blossom. Tuber 


\section{Hybrid Cactus}

ALICE WHITTIER (Reed)

Light primrose yellow, outer rows of petals sharply quilled.

A prize winner whereever it goes. Tuber.....

AMBASSADOR (Broomall)

Soft yellow center, shading to a mber pink on outer petals.

Tuber.

CALIFORNIA ENCHANTRESS (Boston)

Light pink, deepertips. Medium size. Tuber. .50

EDNA FERBER (F. \& M.)

Glistening coral shading to gold at base of petals. Ranks high as a prize winner. Tuber.

\section{ESTHER R. HOLMES (Greinberg)}

Orchid-pink. Medium size, free bloomer, good cut flower. Tuber.

ETHEL M. (Reed)

Amaranth pink, lighter tips, center white. Tuber............ 1.00

GLADYS SHERWOOD (Broomall)

Pure glistening white. Tuber.

KALIF (Engelhardt)

Scarlet. Tuber.

MACGREGOR (Mastick)

Nopal red, free bloomer. Tuber.

\section{PAPILLON (Boston)}

Old-rose with golden lights. Tuber.

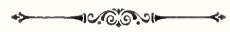

\section{Show}

KING GEORGE (Marean)

Purple shades. Large. Tuber.

SNOWBALL

Pure white. Medium size. Tuber. 


\section{YELLOW COLOSSE}

Primrose yellow. Large. Tuber.

\section{POMPONS}

Your choice of colors: \$4.50 per doz.; \$2.50 per six; $\$ \mathbf{\$ 0 . 5 0}$ each.

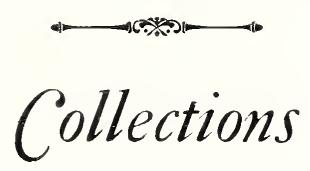

For those who wish to leave the selection of varieties to us, we have arranged collections made up of varieties that are listed in this catalogue, as follows:

5 dahlias all different for $\$ \mathbf{3 . 0 0}$

8 dahlias all different for $\mathbf{5 . 0 0}$

10 dahlias all different for $\mathbf{8 . 0 0}$

$\mathbf{1 5}$ dahlias all different for $\mathbf{1 0 . 0 0}$

Extra Special Selection

6 dahlias all different for $\$ \mathbf{8 . 0 0}$

8 dahlias all different for $\mathbf{1 0 . 0 0}$

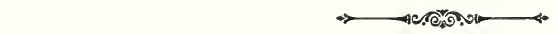

It is our desire and aim to give a feeling of satisfaction in eivery sale.

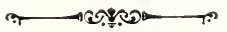

Member of

American Dahlia Society

Dahlia Society of New England 


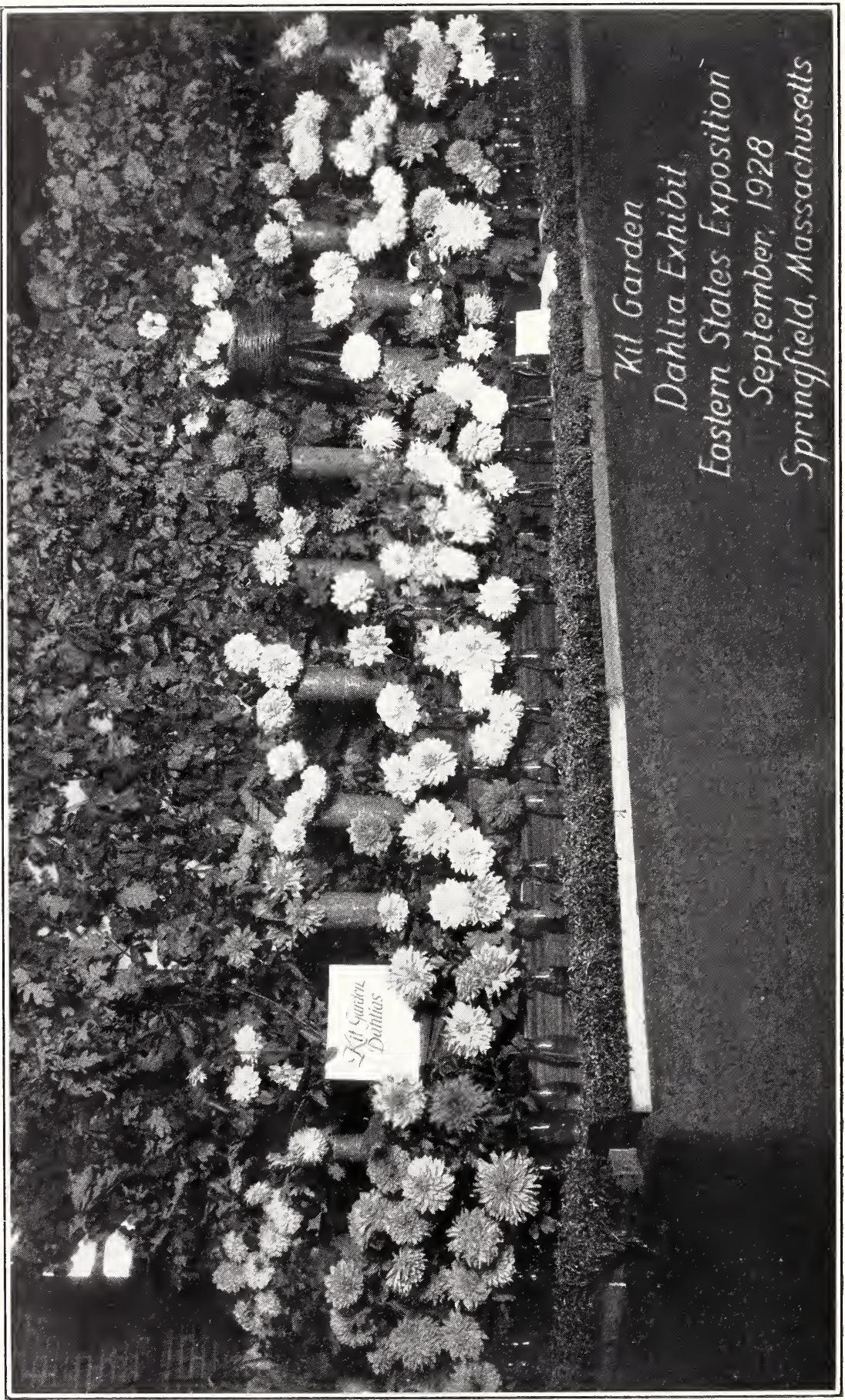



